\title{
Checkpoint Kinase Inhibitor XL844
}

National Cancer Institute

\section{Source}

National Cancer Institute. Checkpoint Kinase Inhibitor XL844. NCI Thesaurus. Code C61102.

A synthetic small-molecule inhibitor of checkpoint kinases 1 and 2 (Chk1 and Chk2) with potential antineoplastic activity. XL844 binds to and inhibits Chks 1 and 2, resulting in inhibition of cell cycle arrest, progressive DNA damage, inhibition of DNA repair, and, ultimately, tumor cell apoptosis. This agent also inhibits vascular endothelial growth factor receptor 1 (VEGFR1) and vascular endothelial growth factor receptor 3 (VEGFR3), important mediators of tumor angiogenesis and lymphogenesis, respectively. In the presence of extensive damage or absence of timely repair, these checkpoint-signaling pathways may also trigger a pathway that effects apoptosis. Normal functions of Chks involve the initiation of cell-cycle arrest and the up-regulation of transcription genes involved with DNA excision repair and dNTP synthesis. 